\title{
HUBUNGAN PEKERJAAN DAN SIKAP IBU MENYUSUI DENGAN PEMBERIAN ASI EKSKLUSIF PADA BAYI USIA 0-6 BULAN DI DESA LEBENG TIMUR KECAMATAN PASONGSONGAN
}

\author{
Nelyta Oktavianisya, Program Studi Ners Universitas Wiraraja \\ e-mail: nelyta2516@gmail.com \\ Sri Sumarni, Program Studi Keperawatan Universitas Wiraraja \\ e-mail: sri.sumarni73@yahoo.co.id
}

\begin{abstract}
Breastfeeding is a natural process but often mothers fail to breastfeed more than they should. Lots of moms who choose not to give Exclusive Breast Milk. The problem of this research is the low level of Exclusive Breastfeeding in Lebeng Timur Village Pasongsongan Sub-district by $4.5 \%$ from the target of $90 \%$. The aim of this research is to determine the relationship between jobs and mother attitude with giving of exclusive ASI in Lebeng Timur Village Pasongsongan Sub District.

The design of this study is Cross Sectional Study. The sample sum a 40 nursing mothers who have infants aged> 6-12 months taken using proportionate random sampling technique. The data analyzed using Chi-square test.

The results showed that some of the respondents work (65\%), had positive attitude (47,5\%), and only (37,5\%) respondents give exclusive breastfeeding. There is a relation between jobs $(p=0.000)$ and the attitude of the breastfeeding mother $(p=0,012)$ whit the exclusive breastfeeding. Mothers, particularly career mothers, are suggested to always give breast milk so that they could promote to the success of exclusive breastfeeding.
\end{abstract}

Keywords: Jobs, Attitude, Exclusive Breastfeeding

\section{PENDAHULUAN}

Menyusui adalah hal yang terjadi secara natural, tetapi ada ibu yang tidak berhasil menyusui tepat sesuai dengan usia bayi yang dianjurkan, ini menjadi dasar agar ibu-ibu mendapat dorongan dan motivasi untuk melakukannya. Berbagai hal yang disampaikan ibu-ibu sebagai alasan yaitu ASI-nya tidak mencukupi atau ada juga yang tidak keluar saat pertama bayi dilahirkan. Sebenarnya sudah banyak media pembbelajaan untuk mengetahui bagaiamana cara untuk memperlancar keluarnya ASI.

Memberikan ASI pada bayi, khususnya Negara berkembang telah mengurangi angka kematian dan keesakitan sekitar satu koma lima juta bayi setiap tahun. World Health Organitation (WHO) menghimbau agar hanya diberikan ASI sampai enam bulan. Indonesia, banyak bayi diselamatkan dari kematian lebih dari 25.000 bayi. Di seluruh dunia1, diselamatkan tiga juta bayi dapat dari kematian dengan memberikan ASI selama enam bulan (DEPKES RI, 2005). Tahun 2001 World
Health Organization (WHO) mengeluarkan anjuran agar negara-negara mengadopsi pemberian ASI eksklusif selama enam bulan. The World Breast-Feeding Trend Initiatives Report yang dipublikasikan tahun 2010 menempatkan Indonesia di posisi ke - 30 diantara 33 negara yang disurvei dalam prevalensi pemberian ASI Eksklusif. Peringkat tersebut masih di bawah Negara-negara seperti Malawi, Zambia dan Ghaza. Survei tersebut menyebutkan hanya 58,7 bayi diantara 150 bayi di Indonesia yang mendapat ASI Ekslusif.

Berdasarkan data profil Dinkes Jatim (2010), diketahui pemberian ASI selama 6 bulan menjadi naik dari 52,3\% (2006) ke 62, 5\% (2009). Sedangkan Pada tahun 2012, ASI Eksklusif di Jawa Timur sudah mencapai $64,5 \%$. Ini merupakan suatu progres yang luar biasa dan signifikan di banding tahun 2010 .

Berdasarkan data Dinkes Kabupaten Sumenep, pada tahun 2012 pemberian ASI di Kabupaten Sumenep cakupannya tergolong kurang sebesar 8, 9\%. Cakupan yang kurang terseebut adalah di UPT Puskesmas 
Pasongsongan yaitu ada 23 bayi $(7,8 \%)$ yang diberikan ASI Eksklusif sebesar 292 bayi. Menurut Dinas Kesehatan Kabupaten Sumenep pencapaian cakupan ASI Eksklusif pada tahun 2010mencapai $25,3 \%$, tahun 2011 mencapai 11,9\%, tahun 2012 mencapai 8,9\%. Sedangkan cakupanASI Eksklusif di wilayah kerja UPT Puskesmas Pasongsongan tahun 2010 mencapai $27,5 \%$, tahun 2011 mencapai 2,4\% dan tahun 2012 mencapai 7,8\%. Kecamatan Pasongsongan, cakupan pemberian ASI Eksklusif yang terendah adalah di Desa Lebeng Timur hanya mencapai $4,5 \%$. Sehingga masalah penelitian adalah rendahnya pemberian ASI Eksklusif di Desa Lebeng Timur Kecamatan Pasongsongan sebesar $4,5 \%$ dari target $90 \%$.

Dalam teori Lawrence Green (Notoatmodjo, 2012), yang menjadi faktor pencetus kurangnya angka pemberian ASI Eksklusif oleh ibu untuk bayi adalah faktor predisposisi salah satunya pekerjaan. Faktor pendukung ialah kuantitas tercukupi sarana pelayanan kesehatan dan keterjangkauan dalam mencapainya (akses pelayanan). Faktor pendorongnya yaitu tidakan petugas kesehatan, dukungan tokoh masyarakat, dukungan keluarga. Lawrence Green juga mengatakan bahwa promkes memiliki peran penting dalam menguatkan bahkan mengubah tiga bagian faktor tersebut supaya sesuai tujuan kegiatan. Hal ini menciptakan tindakan pro masyarakat pada program yang dilakukan atau khususnya terhadap kesehatan.

Survei awal yang peneliti lakukan di Desa Lebeng Timur Kecamatan Pasongsongan didapatkan 8 ibu menyusui. Diketahui bahwa ibu yang merupakan wanita karir sebanyak dan ibu dengan sikap yang kurang untuk pemberian ASI Eksklusif pada bayi masingmasing sebanyak 37, 5\%. Hal ini menjadi dasar untuk dilakukan penelitian yang berjudul hubungan pekerjaan dan sikap ibu dengan pemberian ASI Eksklusif (bayi usia 0-6 bulan) di Desa Lebeng Timur Kecamatan Pasongsongan Kabupaten Sumenep. Sehingga dapat menurunkan bahkan mencegah terjadinya angka kematian pada bayi.

\section{METODE PENELITIAN}

Desain penelitiannya adalah penelitian analitik pendekatan Potong Lintang. Penelitian ini bertujuan mencari hubungan antara pekerjaan dan sikap ibu menyusui. Sampel penelitian diperoleh dengan tekhnik random sampling.

Populasi penelitian yaitu semua ibu dengan bayi usia 7 bulan - 1 Tahun di Desa Lebeng Timur Kecamatan Pasongsongan Kabupaten Sumenep sebanyak 60 responden. Sampel penelitian yaitu semua ibu menyusui dengan bayi 7 bulan - 1 Tahun di Desa Lebeng Timur Kecamatan Pasongsongan sebanyak 40 orang.

Pengumpulan data yang diperoleh dari sumber utama secara langsung (data primer) dilakukan dengan tanya jawab langsung dnegan sumber (wawancara) menggunakan kuesioner. Data data sekunder didapatkan dari Dinkes Kab. Sumenep, Puskesmas, dan Bidan. Uji yang dipilih uji chi-square dimana $\alpha=0,05$.

\section{HASIL PENELITIAN}

Responden sebanyak 40 orang dengan sebaran karakteristik responden menurut umur ibu, pendidikan, pekerjaan, sikap dan pemberian ASI secara Eksklusif dituliskan pada Tabel 1.

Tabel 1. Pengelompokan Responden berdasar Karakteristik

\begin{tabular}{lcc}
\hline \multicolumn{1}{c}{ Karakteristik Responden } & $\mathrm{N}$ & $\%$ \\
\hline Umur Ibu (Tahun) & & \\
$\quad \leq 20$ & 5 & 12,5 \\
$21-30$ & 26 & 65 \\
$31-40$ & 9 & 22,5 \\
\hline Pendidikan & & \\
SD/MI & 23 & 57,5 \\
SMP/MTS & 11 & 27,5 \\
SMA/MA & 3 & 7,5 \\
S1 & 3 & 7,5 \\
\hline Pekerjaan & & \\
Petani & 20 & 50 \\
PNS & 1 & 2,5 \\
Swasta & 5 & 12,5 \\
Ibu rumah tangga & 14 & 35 \\
\hline Sikap Ibu & & \\
Positif & 19 & 47,5 \\
Negatif & 21 & 52,5 \\
\hline Pemberian ASI Eksklusif & & \\
Memberi ASI Eksklusif & 15 & 37,5 \\
Non ASI Eksklusif & 25 & 62,5 \\
\hline
\end{tabular}


Dari tabel tersebut dapat dilihat bahwa sebagian besar usianya 21-30 tahun (65\%), sebagian besar responden tingkat pendidikannya SD / MI (57,5\%), setengahnya responden bekerja sebagai petani (50\%), sebagian besar responden memiliki sikap negatif $(52,5 \%)$ dan sebanyak $25(62,5 \%)$ Ibu yang tidak memberikan ASI Eksklusif

Tabel 2. Tabulasi silang antara pekerjaan dengan pemberian ASI Eksklusif di Desa Lebeng Timur Kec. Pasongsongan Kab. Sumenep Tahun 2018.

\begin{tabular}{|c|c|c|c|c|c|c|}
\hline \multirow{3}{*}{ Pekerjaan } & \multicolumn{4}{|c|}{ Pemberian ASI Eksklusif } & \multirow{3}{*}{ Jumlah } & \multirow{3}{*}{$\begin{array}{c}\text { Persentase } \\
(\%)\end{array}$} \\
\hline & \multicolumn{2}{|c|}{ Memberi } & \multicolumn{2}{|c|}{ Tidak Memberi } & & \\
\hline & $\sum$ & $\%$ & $\sum$ & $\%$ & & \\
\hline Bekerja & 8 & 30,77 & 18 & 69,23 & 26 & 100 \\
\hline Tidak Bekerja & 13 & 92,86 & 1 & 7,14 & 14 & 100 \\
\hline Jumlah & 21 & 52,5 & 19 & 47,5 & 40 & 100 \\
\hline \multicolumn{3}{|c|}{$\begin{array}{l}\text { Tabel 2. dapat dilihat bahwa sebagian besar } \\
\text { ibu bekerja tidak memberikan ASI sebesar } \\
(69,23 \%) \text {. Hampiir seluruhnya ibu tidak } \\
\text { bekerja tetapi memberikan ASI Eksklusif } \\
\text { sebesar }(92,86 \%) \text {. Hasil uji diketahui p value = }\end{array}$} & \multicolumn{4}{|c|}{$\begin{array}{l}0,000 \text { dimana } \alpha=0,05 \text { bermakna ada } \\
\text { hubungan pekerjaan dengan status pemberian } \\
\text { Air Susu Eksklusif di Desa Lebeng Timur } \\
\text { Kecamatan Pasongsongan Kabupaten } \\
\text { Sumenep Tahun 2018. }\end{array}$} \\
\hline
\end{tabular}

Tabel 3. Tabulasi silang antara sikap dengan status pemberian ASI Eksklusif di Desa Lebeng Timur Kec. Pasongsongan Kab. Sumenep Tahun 2018.

\begin{tabular}{|c|c|c|c|c|c|c|}
\hline \multirow{3}{*}{ Sikap } & \multicolumn{4}{|c|}{ Pemberian ASI Eksklusif } & \multirow{3}{*}{ Total } & \multirow{3}{*}{$\begin{array}{c}\text { Persentase } \\
(\%)\end{array}$} \\
\hline & \multicolumn{2}{|c|}{ Memberi } & \multicolumn{2}{|c|}{ Tidak Memberi } & & \\
\hline & $\sum$ & $\%$ & $\sum$ & $\%$ & & \\
\hline Positif & 16 & 84,21 & 3 & 15,79 & 19 & 100 \\
\hline Negatif & 5 & 23,81 & 16 & 76,19 & 21 & 100 \\
\hline Total & 21 & 52,5 & 19 & 47,5 & 40 & 100 \\
\hline
\end{tabular}

Berdasarkan tabel 3. Menunjukkan bahwa hampir seluruhnya ibu yang mempunyai bayi usia 7 bulan - 1 tahun memiliki sikap positif memberikan ASI Eksklusif sebesar (84,21\%). Dan hampir seluruhnya ibu yang mempunyai bayi usia 7 bulan - 1 tahun memiliki sikap negatif tidak memberikan ASI Eksklusif sebesar $(76,19 \%)$. Hasil uji diketahui $\mathrm{p}$ value $=$ $0,012<\alpha=0,05$, yang bermakna ada hubungan sikap dan pemberian ASI.

\section{PEMBAHASAN}

1. Hubungan Pekerjaan dengan Status Pemberian ASI Eksklusif di Desa Lebeng Timur Kec. Pasongsongan Kab. Sumenep

Dari hasil uji staatistik, hasil $\mathrm{p}=0,000$ dimana $\alpha=0,05$ bermakna terdapat hubungan antara pekerjaan denngan status pemberian air susu Eksklusif. Teori Lawrence Green dalam Notoatmodjo (2012) faktor yang menyebabkan kurangnya pemberian air susu Eksklusif adalah faktor predisposisi salah satunya pekerjaan. Faktor pendukung yaitu adanya sarana pelayanan kesehatan dan mudah dalam mencapai tempat pelayanan kesehatan (akses pelayanan). Faktor pendorong yaitu tindakan petugas kesehatan, dukungan toma, dukungan keluarrga.

Penelitian ini sama dengan yang dilakukan Juliastuti (2011) yang menyatakan pemberian air susu eksklusif oleh ibu yang tidak bekerja akan semakin tinggi. Sedangkan ibu yang bekerja mempunyai keterbatasan menyusui bayi secara langsung. Jika pengetahuan ibu cukup mengenai kegunaan, cara menyimpan, termasuk juga pemberian air susu eksklusif maka dapat meningkatkan pemberian air susu eksklusif. Uchenna (2012) mengatakan bahwa tempat ibu bekerja juga meemiliki peranan yang besar dalam memberi dukungan terhadap tercapainya pemberian ASI eksklusif. Hal ini dikarenakan ibu harus kembali bekerja kurang dari 6 bulan setelah bayi dilahirkan (kurang lebih 3 bulan). Galson dalam Uchenna (2012) menyatakan bahwa kewajiban ibu kembali bekerja, menjadi alasan untuk tidak melanjutkan pemberikan ASI eksklusif ke bayinya.

Menurut teori ibu menyusui yang bekerja berpengaruh pada keberhasilan ibu 
dalam memberikan ASI Eksklusif. Bekerja sambil menyusui, biasanya membutuhkan waktu yang banyak dan berulang-ulang, dituntut adanya kesungguhan dan konsentrasi serta keseriusan.Tantangan besar ketika seseorang sedang berusaha untuk menghadapi keadaan yang lebih baik dan berusaha menjadikan kehidupan lebih berarti.

2. Hubungan Sikap Ibu Menyusui dengan Status Pemberian ASI Eksklusif Pada Bayi Usia 0-6 Bulan di Desa Lebeng Timur Kec. Pasongsongan Kab. Sumenep

Hasil uji didapatkan $p=0,012$ dimana $\alpha=$ 0,05 artinya terdapat hubungan antara sikap ibu menyusui dengan status pemberian Air susu Eksklusif. Sikap merupakan suatu kebiasaan seseorang untuk memilih memberikan atau tidak memberikan ASI. Maka untuk mengubah sikap ibu agar menyusui bayinya harus memberikan konseling dan pendekatan pada ibu serta memberikan penyuluhan agar dapat mengubah sikap ibu. Pemberian ASI Eksklusif dapat meningkat jikaa ibu mempunyai sikap positif.

Menurut Ahmadi (2000) terjadinya tidak akan terjadi perubahan sikap secara alami atau sendirinya. Terbentuk sikap ditentukan oleh hubungan orang, obyek, lembaga, kelompok, nilai. Baik melalui hubungan antar individu, hubungan di dalam keloompok, komunikasi surat kabar, media elektronik, dan sebagainya. Ada dua sikap pada seseorang yaitu dapat berupa positif dapat juga bersifat negatif.

Penelitian yang dilakukan Widiyanto dalam Wowor (2013) menyatakan bahwa sikap ibu dalam pemberian ASI masih kurang. Lingkungan sekitar mengambil andil dalam mempengaruhi hal tersebut. Keputusan yang terbaik dipengaruhi oleh lingkungan terdekat. Pada saat ini banyak promosi sufor yang dianggap praktis dan mudah oleh ibu-ibu. Hasil penelitian terdahulu yang dilakukan Sofiyatun dalam Hartatik (2009) menytakan terdapat hubungan sikap ibu dengan keberhasilan dalam memberikan air susu eksklusif.

Dengan adanya penelitian ini disarankan pada ibu untuk menyusui bayinya sampai berusia 6 bulan, hal ini dikarenakan ASI Eksklusif dapat memberikan kekebalan secara langsung dari seorang ibu kepada bayinya, sehingga bayi tidak mudah terserang penyakit, mencerdaskan otak bayi dalam berinteraksi serta mewujudkan emosional ibu dan bayinya.

\section{KESIMPULAN}

1. Setangahnya ibu yang menyusui di Desa Lebeng Timur adalah bekerja sebagai petani.

2. Sebagian besar ibu yang menyusui di Desa Lebeng Timur memiliki sikap negatif.

3. Sebagian besar ibu di Desa Lebeng Timur tidak menyusui secara Eksklusif.

4. Terdapat hubungan pekerjaan ibu menyusui dengan pemberian air susu Eksklusif di Desa Lebeng Timur Kecamatan Pasongsongan

5. Ada hubungan sikap ibu menyusui dengan kebrhasilan dalam memberikan air susu Eksklusif di Desa Lebeng Timur Kecamatan Pasongsongan.

\section{DAFTAR PUSTAKA}

Abu Ahmadi. 2000. Psikologi Sosial. Jakarta: Rineka Ilmu

Azwar, Saifuddin (2007), Sikap manusia Teori dan Pengukurannya, Jakarta: Rineka Cipta.

Fikawati S, dan Syafiq A. 2010. Kajian Implementasi dan Kebijakan Air Susu Ibu Eksklusif dan Inisiasi Menyusu Dini di Indonesia. Jurnal Makara, kesehatan, Vol.14, No.1, Juni 2010 : 17-24.

Hatatik, Tri (2007) Hubungan Pengetahuan dan Sikap Ibu dengan Pemberian Asi Eksklusif di Kelurahan Gunungpati Kecamatan Gunungpati Kota Semarang Tahun 2009. Skripsi.

Hidayat, A. Aziz (2007) Riset Keperawatandan Teknik Penulisan Ilmiah, Jakarta Salemba Medika.

Hidayat, A. Aziz (2008) Pengantar Ilmu Keperawatan, Jakarta : Salemba Medika.

Juliastuti, R. 2011. Hubungan Tingkat Pengetahuan, Status Pekerjaan Ibu, dan Pelaksanaan Inisiasi Menyusu Dini dengan Pemberian ASI Eksklusif. Tesis. Program Studi Magister Kedokteran Keluarga, Universitas Sebelas Maret Surakarta. 
Klein, S., Miller, S., \& Thomson, F. (2004). Bila Perempuan Melahirkan;Panduan Mengenai Persalinan.Yogyakarta : Insist Press.

Notoatmodjo, S (2003) Pendidikan dan Perilaku Kesehatan ,Jakarta :Rineka Cipta.

Notoatmodjo, Soekidjo (2007) Promosi Kesehatan dan Ilmu Perilaku,Jakarta :Rineka Cipta.

Nursalam (2011) Konsep dan Penerapan Metodologi Penelitian Ilmu Keperawatan, Jakarta :Salemba Medika.

Proverawati, A., dan Asfuah, A. (2009).Buku Ajar Gizi untuk Kebidanan. Yogyakarta : Nuha Media.

Proverawati A., dan Rahmawati, E. (2010). Kapita Selekta ASI dan Menyusui.Yogyakarta : Nuha Media.
Roesli, U. (2007). Mengenal ASI Eksklusif. Jakarta : Trubus Agriwidya

Sudiharto.(2007). Asuhan Keperawatan Keluarga Dengan Pendekatan Keperawatan Transkultural. Jakarta : EGC.Sunaryo (2004) Psikologi Untuk Keperawatan, Jakarta : EGC.

Uchenna, O. (2012). Problems Encountered by Breastfeeding Mothers in Their Practice of Exclusive Breast Feeding in Tertiary Hospitals in Enugu State, South-East Nigeria. International Journal of Nutrition and Metabolism, 4(8), 107-113.

Utami, R (2005) Mengenal Asi Eksklusif, Jakarta : PT Elex Komputindo.

Wowor, Mariane dkk (2013). Hubungan Pengetahuan dan Sikap dengan Pemberian Asi Eksklusif pada Ibu Menyusui di Puskesmas Bahu Kota Manado. Ejurnal Keperawatan (e-Kp) Volume 1. Nomor 1. Agustus2013 